\title{
Hot Isostatic Pressing of SY625 Powder
}

\author{
D. Lasalmonie ${ }^{*}$, C. Dellis ${ }^{*}$, P.Stutz ${ }^{* *}$, J.C. Garcia ${ }^{* * *}$, and J.P. Bulhe ${ }^{* * *}$ \\ * CEA/CEREM - 17, rue des Martyrs, 38054 Grenoble Cedex 9, France \\ ${ }^{* *}$ L3S, BP53X, 38041 Grenoble Cedex, France \\ *** TURBOMECA, 40220 Tarnos, France
}

\begin{abstract}
$\underline{\text { Austract }}$
Hot Isostatic Pressing (HIP) is an established process for compacting powder materials far below their melting point. It allows to produce net-shape parts in order to reduce machining costs or to obtain non machinable geometries. In the HIP process, a steel container is filled with the superalloy powder, out-gassed, and then submitted to simultaneous application of high pressure (about 100MPa) and a temperature of about $1150^{\circ} \mathrm{C}$ for several hours. Porosity is then completely eliminated.

To produce net-shape parts, it is essential to be able to forecast the belaviour of the powder and steel container during the HIP process in order to predict the final geometry of the product. Numerical simulation can provide much information about the final as well as intermediate stages of the HIP process.

The use of simulation requires the constitution of materials data files containing physical and thermo-mechanical properties of the materials, including coefficients of the porous constitutive equations for powder. In this work, the SY62.5 data not available in the literature have been determined experimentally. Uniaxial compression tests have been used to determine creep law parameters for dense and porvus materials. Data base for steel container is also available for a large range of temperature.
\end{abstract}

\section{Aknowledgements}

This study has been supported by TURBOMECA. It has been done in the scope of the IsoPREC agreement between TURBOMECA, SEP, TECPHY and CEA/CEREM.

$\underline{\text { References }}$

[1] Lasalmonie D., LeBer L., Dellis Ch. "PreCAD, a computer assisted design and modelling tool for superalloy powder precision moulding" (Paper presented at the 8 th International Symposium on Superalloys, 1996)

[2] Abouaf $M$, Chenot J.L. "Simulation numérique de la déformation à chaud de poudres metalliques" Journal de Mécanique Théorique Appliquée, 5 (1986), 121

[3] Green R.J. "A plastic theory for porous solid" International Journal of Mechanical Science, 14 (1972), 215-224

[4] Zhao D., Chaudhury P.K., Franck R.B., Jackman L.A. "Flow behavior of three 625-type alloys during high temperature deformation" (Paper presented at Superalloys 718,625,706 and Various Derivatives, 1994) 315-329
[5] Alniak O., Morphy D.D., Terada T., Koul A.K., Immarigeon J.P. "Modelling of Deformation and Microstructural Changes in P/M René 95 under Isothermal Forging Conditions" (Paper presented at the Agard Conference, 1987) $n^{\circ} .426 .2-1$

[6] Abondance D. "Modélisation thermomecanique d'un procédé de mise en forme aux cotes de pièces complexes par compaction isostatique à chaud de poudre de TA6V" (Ph.D. Thesis, Université Joseph Fourier - Grenoble 1; Spécialité Mécanique, 06 février 1996)

[7] Bouaziz O., Baccino R., Dellis Ch., Moret F., Stutz P. "Thermomechanical behavior of an austenitic stainless steel powder consolidated by hot isostatic pressing" (Paper presented at PM ${ }^{2}$ TEC'96 June 16-21, 1996, Washington DC)

\footnotetext{
Superalloys $718,625,706$ and Various Derivatives Edited by E.A. Loria

The Minerals, Metals \& Materials Society, 1997
} 


\section{Introduction}

Hot Isostatic Pressing (HIP) is an established process for compacting powder materials far below their melting point. Processing of superalloy powders using HIP has becn used for many years in different industrial applications, especially to produce high quality parts with complex geometry. In the HIP process, a steel container is filled with superalloy powder, ou gassed and then submitted to simultaneous application of high pressure (about $100 \mathrm{MPa}$ ) and a temperature of about $1150^{\circ} \mathrm{C}$ for several hours. During the process, porosity is completely eliminated, so volume is reduced of about $30 \%$. It is important to obtain net-shape HIP parts in order to reduce machining costs or even to produce non-miachineable geomelites. However, the final geometry of the product can not be simply deduced from the initial one, due to container stiffness and temperature gradients during consolidation process. To produce net-shape parts, it is essential to be able to forecast the behaviour of the superalloy powder and steel container during HIP process in order to predict the final geometry of the product. Numerical simulation can provide much information about the final as well as intermediate stages of the HIP process.

A special tool has been developped by CEA/CEREM in the frame of the ISOPREC ${ }^{\infty}$ project for the design and modelling of container used to produce net-shape parts using Hot Isostatic Pressing (HIP). This tool is constituted of three modules : PreCAD $\% / D$ for the design of the parts and meshing, $\operatorname{PreCAD} / \mathrm{M}$ for the modelling of consolidation of the powder, and $\mathrm{PreCAD}^{\Phi} / \mathrm{B}$ for the data base of materials including powders and container. A detailed description of this tool is given in a previous paper [1]. We will only detail here the constitution of the material data file and especially the determination of parameters of the constitutive law used for the simulation.

The superalloy considered in this study is the SY625, a soltd solution-strenghtened nickel base superalloy produced by TECPHY, France. Its composition is given in table I.

Table I: Chemical analysis of the SY625 (in \% weight)

\begin{tabular}{|c|c|c|c|}
\hline $\mathbf{N i}$ & Bal. & $\mathbf{C o}$ & 0.014 \\
\hline $\mathbf{C r}$ & 20.4 & $\mathbf{F e}$ & 0.2 \\
\hline $\mathbf{M o}$ & 8.6 & $\mathrm{Si}$ & 0.18 \\
\hline $\mathbf{N b}$ & 3.4 & $\mathbf{T i}$ & 0.01 \\
\hline $\mathbf{C}$ & 0.013 & \multicolumn{2}{|c}{} \\
\cline { 1 - 3 } & & &
\end{tabular}

\section{Description of the theoretical model}

Inorder to simulate consolidation of powder, a macromechanical approach is used. Powder is considered as a continuous medium with relative density as an internal variable. The relative density $\rho$ is defined as the ratio of the apparent density to the density of the fully dense material. The behaviour of the powder during consolidation is modelled by constitutive equations based on continuous media mechanics for viscoplastic metals. The flow formulation for compressible viscoplastic materials proposed by Abouaf [2] is used. This model extends, for hot deformation, the Green's approach [3] for cold deformation.

Constitutive equations for porous materials are developed in the framework of continuous mechanics. It is an extension of the classical $\mathrm{J}_{2}$ Mises theory allowing volume changes during viscoplastic flow. The equivalent stress $\sigma_{\mathrm{eq}}$, which includes the effect of pressure, is defined as:

$\sigma_{e q}=\sqrt{f S_{1}^{2}+3 / 2 c \bar{S}_{2}^{2}}$

with

$\mathrm{S}_{1}=\operatorname{Tr}(\tilde{\sigma})$

$\overline{\mathrm{S}}_{2}^{2}=\operatorname{Tr}(\tilde{\bar{\sigma}} . \tilde{\bar{\sigma}})$

$\widetilde{\bar{\sigma}}=\tilde{\sigma}-\frac{1}{3} S_{1} \tilde{\delta}$

first invariant of the stress tensor

second invariant of the stress tensor

deviator of the stress tensor

where $\tilde{\sigma}$ is the Cauchy stress tensor and $\tilde{\delta}$ is the unity second order tensor. $\mathrm{c}$ and $\mathrm{f}$ are two functions representing the stress localisation induced by porosity, and which a priori depend only on the relative density $\rho$. For full density $(\rho=1), c=1$ and $f=0$ so that the equivalent stress defined for the porous metal is equivalent to the classical Mises equivalent stress.

\section{Identification of the parametcrs}

In order to identify those two parameters we made experiments inwhich the then to have an analytical expression for $f$ and $c$.

- During a Hot Isostatic Pressing of a cylinder where the compact duesn't reach the full density, we have

$$
f=\frac{1}{9}\left(\frac{\dot{\rho} / \rho}{A p^{n}}\right)^{2 / n+1}
$$

$\rho(t)$ is the evolution of the relative density with the step duration ( pressure and temperature being constant) of the HIP cycle, $\dot{\rho}$ is its derivation. $\mathbf{P}$ is the applied pressure.

$A$ and $n$ are the parameters of a Norton creep law for the dense material. They are independent from the density and are identified on the dense material using uniaxial compression tests at different temperatures and strain rates.

- During a high temperature compression of porous samples, we can reach 


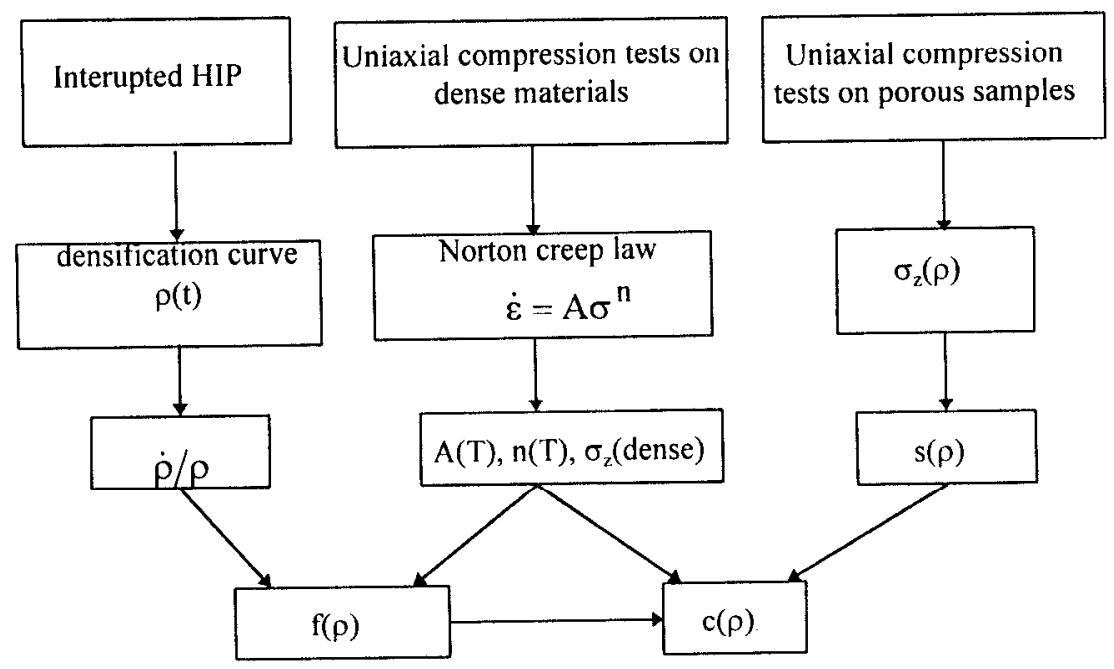

Figure.1: General framework of the experimental determination

$$
\text { with } \begin{aligned}
c & =s^{-2 n / n+1}-f \\
s & =\frac{\sigma_{z}(\rho)}{\sigma_{z}(\text { dense })}
\end{aligned}
$$

where $s$ is the ratio of the yield stress of porous sample on the yield stress of the dense one.

The experimental function $s(\rho)$ is first determined, then the rheological function $\mathrm{c}$ is calculated.

This identification method is summarized in figure I.

\section{Interupted HIP}

$f$ is density dependent, we must therefore choose $\mathrm{I}$ and $\mathrm{P}$ in order to have a densification curve with a large range of density. Because of the high temperature and pressure of the industrial cycle $\left(1150^{\circ} \mathrm{C}\right.$ and $\left.100 \mathrm{MPa}\right)$, the compact at the end of the raising is close to be dense, thus we choose $950^{\circ} \mathrm{C}, 20 \mathrm{MPa}$ and $950^{\circ} \mathrm{C}, 60 \mathrm{MPa}$. (figure 2). Those two cycles have the same duration of the simultaneous temperature and pressure raising, 54 min. For each HIP cycle, different step durations have been performed. The relative density is then ranging from $78 \%$ to $97 \%$ of the dense material, the tap density being $73 \%$; this high value is the consequence of the large dispersion of the powder's granulometry. A simple time derivation of the interpolated curves, $\rho(t)$ is then performed to obtain the master curves relating the densification rate to the relative density. From those curves and knowing the creep parameters, it is possible to establish the curve $f(\rho)$.

\section{Creep law parameters}

The simulation requires the knowledge of the creep law for all the involved materials: the SY 625 powder and the mild steel the container is composed of. We performed uniaxial compression tests at all the temperatures (from $900^{\circ} \mathrm{C}$ to $1150^{\circ} \mathrm{C}$ ) and strain rates (from $4.10^{-6} \mathrm{~s}^{-1}$ to $10^{-3} \mathrm{~s}^{-1}$ ) that the materials are liable to undergo.

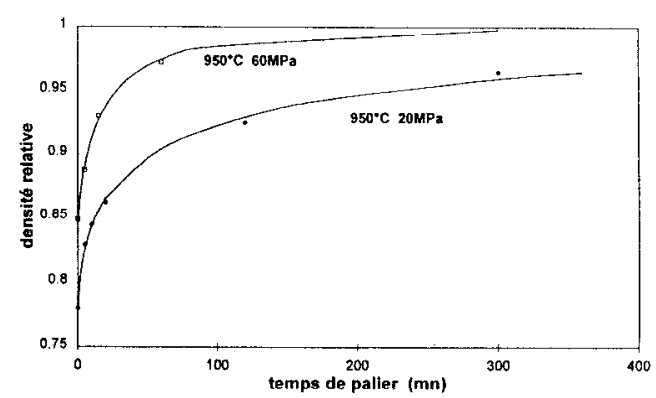

Figure. 2: Densification curves of SY 625 at $950^{\circ} \mathrm{C} 20 \mathrm{MPa}$ and $60 \mathrm{MPa}$.

The experiments were conducted with a $10 t$ press fit out with a high temperature halogen lamp furnace, at constant cross bar speed with the strain rate jump method.

The dense samples of nickel based superalloy $\$ Y 625$ were hipped at $950^{\circ} \mathrm{C}, 1000^{\circ} \mathrm{C}, 1050^{\circ} \mathrm{C}$ and $1150^{\circ} \mathrm{C}$ and the compression tests were made between $950^{\circ} \mathrm{C}$ and $1100^{\circ} \mathrm{C}$. The results are given in table II

They show a great difference from bibliographic data especially [4] where $\mathrm{n}$ decrease from 6 to 4 between $900^{\circ} \mathrm{C}$ and $1150^{\circ} \mathrm{C}$ The coefficient of stress sensivity, $\mathrm{n}$, seems to be almost constant around 2.2, if the test temperature is equal to the HIP temperature, whereas it undergoes a great jump if the test temperature is lower than the HIP temperature. We compare those values with the grain coarsening during HIP (fig. 3). It seems that the two values are related.

The $n$ value is thus the result of two competing phenomenons: on one hand, $\mathbf{n}$ may decrease with increasing temperature, but on the other hand, it may increase with increasing grain size [5].

All we can conclude now is that the temperature of fabrication, and then the grain size, has a strong influence on the creep properties of the P/M SY 625 alloy. 
Table II: Creep law parameters of the P/M SY625

\begin{tabular}{|c|c|c|c|c|c|c|}
\hline Test T $^{\circ} \mathrm{C}$ & \multicolumn{3}{|c|}{950} & 1000 & 1050 & 1100 \\
\hline HIP T ${ }^{\circ} \mathrm{C}$ & 950 & 950 & 1150 & 1000 & 1050 & 1150 \\
\hline $\mathrm{n}$ & 2.4 & 2.2 & 3.8 & 2.3 & 2 & 2.1 \\
\hline
\end{tabular}

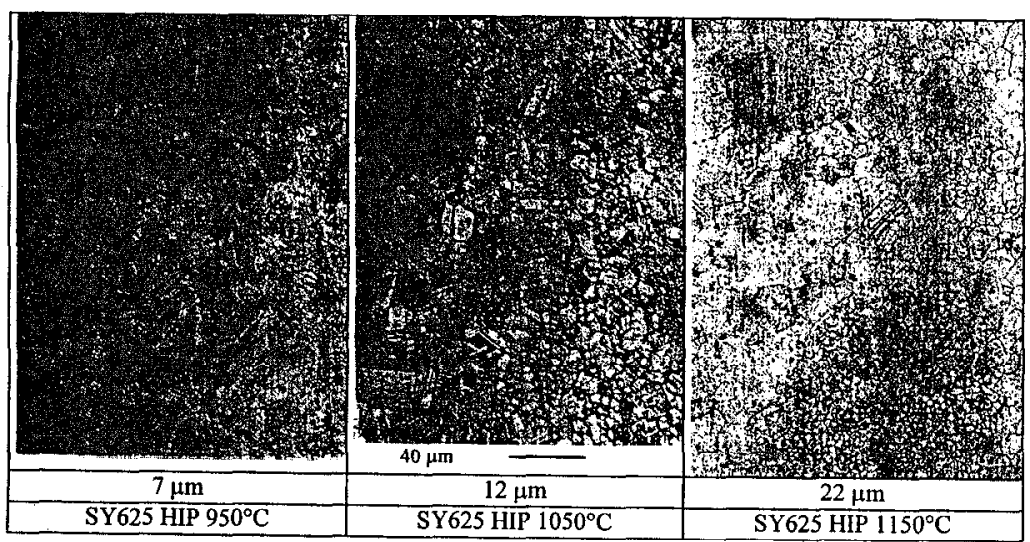

figure. 3: photomicrographs of P/M SY625 after HIP at $100 \mathrm{MPa}$ and $950^{\circ} \mathrm{C}, 1050^{\circ} \mathrm{C}, 1150^{\circ} \mathrm{C}$ and the corresponding mean grain size.

We have chosen to determine the creep law at the same temperature the samples have been hipped in order to have in the data base the $A$ and $n$ values of the material in a state as close as possible as it is during the heating up.

\section{Uniaxial compression tests on porous samples}

The porous samples obtained from interupted HIP cycles underwent uniaxial compression tests at $950^{\circ} \mathrm{C}$ at a strain rate of $10^{-4} \mathrm{~s}^{-1}$. The $\mathrm{s}$ function is then plotted for density ranging from $78 \%$ to $100 \%$ of the relative density. We made in addition one test on a sample hipped at $1050^{\circ} \mathrm{C} 20 \mathrm{MPa}(\rho=88 \%)$

\section{The rheological functions $f$ and $c$}

The densification curves and the knowledge of the creep law allow to identify $f$ on a large scale of density (figure 4). The $c$ function follows the compression tests on porous samples (figure 5).

The sample hipped at $1050^{\circ} \mathrm{C} 20 \mathrm{MPa}$, the two densification curves (20 MPa and $60 \mathrm{MPa}$ ) and the few difference it leads in the rheological functions justify the Abouaf's hypothesis: $f$ and $c$ are not dependent on the pressure and temperature; what confirms results of previous studies made on TA6V [6] and $316 \mathrm{LN}$ [7]

\section{Conclusions}

The data base needed to simulate the consolidation of $\mathrm{P} / \mathrm{M}$ SY625 consists of two rheological parameters ( $f$ and $c$ ) and some physical properties such as Young modulus, Poisson's ratio, thermal expansion coefficient, creep properties, thermal conductivity, .... .

The $f$ and $c$ coefficients have been experimentally determined. This study justifies one of the main hypothesis of the Abouaf's law: $f$ and $c$ are independent of temperature and pressure.

The other parameters are known from a bibliographic study.

The next step is now to use PreCAD ${ }^{8}$ to simulate HIP consolidation of SY625 powder to manufacture net shape parts using ISOPREC ${ }^{(\oplus)}$

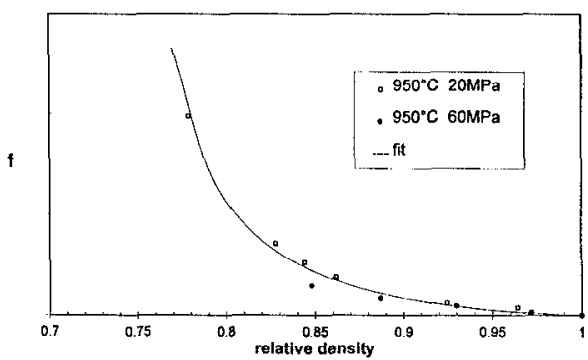

Figure. 4: Shape of the f function of P/M SY625

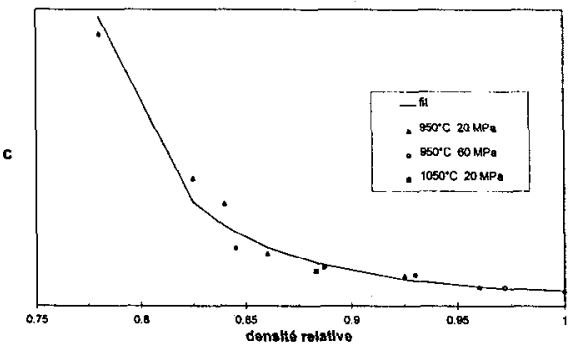

Figure 5: Shape of the $\mathrm{c}$ function of P/M SY625 